УДК 313.13

ББК 65.04

ПОЛЕЗНОСТНАЯ (ПОТРЕБИТЕЛЬНО-СТОИМОСТНАЯ) КОНЦЕПЦИЯ ЭКОНОМИЧЕСКОЙ ТЕОРИИ И ЕЕ ИСПОЛЬЗОВАНИЕ В СТРОИТЕЛЬНОЙ ИНДУСТРИИ ДЛЯ ОЦЕНКИ ЭФФЕКТИВНОСТИ НОВОЙ ТЕХНИКИ

\author{
В. Ф. БАЙНЕВ \\ доктор экономических наук, профессор, \\ заведующий кафедрой инновационного менеджмента \\ Белорусский государственный университет \\ Минск, Республика Беларусь \\ Ю. Ю. РУНКОВ \\ младший научный сотрудник кафедры инновационного менеджмента \\ Белорусский государственный университет \\ Минск, Республика Беларусь
}

Статья посвящена дальнейшему развитию полезностной (потребительно-стоимостной) конщепции экономической теории путем ее распространения на новую предметно-объектную область - строительную индустрию. Предложена методика расчета полезностного экономического эффекта и полезностной экономической эффективности строительной техники, использующей углеводородное топливо и электрическую энергию. Приведены результаты апробации данной методики применительно к конкретным образиам строительной техники. Показано, что данная методика позволяет оценить (сравнить) результативность использования строительной техники с точки зрения основного экономического предназначения всякой техники сберегать труд человека.

Ключевые слова: полезностная (потребительно-стоимостная) концепция, полезность, потребление, потребительная стоимость, строительная отрасль.

\title{
USEFUL (CONSUMER-VALUE) CONCEPT ECONOMIC THEORY AND ITS USE IN STROWNINGS FOR EVALUATING EFFICIENCE OF NEW TECHNICS
}

\author{
V. F. BAJNEV \\ Doctor in Economics, Professor, \\ Head of the Chair «Innovative management» \\ Belarusian State University \\ Minsk, Republic of Belarus \\ $\mathrm{Yu}$. Yu. RUNKOV \\ Junior research associate of the Chair «Innovative Management» \\ Belarusian State University \\ Minsk, Republic of Belarus
}

The article is sanctified to the further development of the utility (use-value) concept of economic theory by its spread to a new subject-object area - the construction industry. A technique for calculating the utility economic effect and the utility economic efficiency of construction equipment using hydrocarbon fuels and electric energy is proposed. Results over of approbation of this methodology are brought as it applies to the certain standards of building technique. It is shown that this methodology allows to estimate (to compare) effectiveness of the use of building technique from the point of view of basic economic destiny of every technique to save labour of man. 
Keywords: utility (consumptive-valuable) consept, utility concept, utility, consumption, construction industry.

\section{ВВЕДЕНИЕ}

Нынешний этап развития человеческой цивилизации, на наш взгляд, наиболее точно характеризуется термином «четвертая промышленная (индустриальная) революция». Его автор - основатель и бессменный президент Всемирного экономического форума в Давосе немецкий экономист К. М. Шваб так описывает связанные с этим феноменом грандиозные изменения: «Мир преображается на наших глазах. Новые технологии меняют жизнь, убеждения и ценности. Человечество стоит на краю новой технологической революции, которая кардинально изменит то, как мы живем и работаем, и относимся друг к другу. Подобного масштаба и сложности перемен человечеству еще никогда не доводилось испытывать» [1].

Вместе с тем было бы большой ошибкой считать, что указанные революционные изменения ограничиваются лишь технико-технологическими аспектами человеческого бытия. Столь же масштабные трансформации, на наш взгляд, должны произойти и в экономической науке. В настоящее время исчерпавшие себя традиционные стоимостные критерии эффективности экономических систем, нацеливающие их на достижение максимальной прибыли любой ценой, уже поставили человечество на грань энергетической, сырьевой, экологической катастрофы. Неслучайно крупный белорусский экономист С. Ю. Солодовников пишет: «Глобальная социально-технологическая революция, свидетелями и участниками которой мы все являемся, по своему значению и последствиям затмевает те лежащие на поверхности проблемы и вызовы, с которыми столкнулось сегодня человечество, страны и народы. Человечество начинает по-новому смотреть на цели и критерии общественного прогресса. Глобальные цивилизационные трансформации нашли свое отражение и в эволюции предмета экономической теории. Постепенно, сначала исподволь, а потом и все более явно, уже к концу прошлого века, на смену узко экономическим концепциям... приходят социально-институциональные концепции, позволяющие увидеть в социальных экономических отношениях основу функционирования любой национальной экономической модели» [2, с. 7].

Мы убеждены, что решение глобальных (энергетической, сырьевой, экологической, продовольственной, демографической и т. д.) проблем цивилизации принципиально невозможно в рамках традиционных представлений о максимизации прибыли как главной цели функционирования экономических систем. Более того, мы убеждены, что эти представления собственно и являются первопричиной указанных проблем. И действительно, именно погоня за максимальной и быстрой прибылью заставляет предпринимателей сливать неочищенные отходы производства прямо в реку, вместо использования возобновляемых источников энергии наращивать сжигание углеводородов, масштабно применять рабский труд мигрантов и «гастарбайтеров», вместо здоровой пищи торговать ее суррогатами, вырубать леса, ничуть не заботясь об их восстановлении и т. д.

Приходится констатировать, что критерий максимизации прибыли вопреки утверждениям нынешнего «экономического мейнстрима» зачастую дает ложные сигналы при выборе оптимальных направлений развития цивилизации. Торговля алкоголем, табаком, наркотиками, оружием, фальсифицированными продуктами и лекарствами, людьми, их органами и т. п. - вот наиболее прибыльные виды бизнеса, полезность которых для общества, однако, весьма сомнительна. Должно ли, имеет ли право человечество развиваться по этим хотя и прибыльным, но антиполезным направлениям? 
На наш взгляд, той «основой функционирования любой национальной экономической модели», о которой ведет речь проф. С. Ю. Солодовников, должна быть не максимизация прибыли, а иные критерии, нацеливающие функционирование социально-экономических на удовлетворение не сиюминутных, а фундаментальных, глубинных потребностей человека и человечества в целом. Иными словами, на смену традиционной стоимостной концепции экономической теории, по нашему убеждению, должна прийти полезностная система экономических знаний, ориентирующая деятельность экономических систем на максимизацию полезностных (потребительно-стоимостных) характеристик производимых ими товаров и услуг.

В настоящее время теоретические основы потребительно-стоимостной концепции достаточно детально развиты в работах ряда российских и белорусских ученых (В. Я. Ельмеев, С. С. Губанов, Н. Ф. Дюдяев, Е. А. Дадеркина и др.). Однако до настоящего времени потребительно-стоимостному анализу были подвергнуты труд как фактор производства (В. Я. Ельмеев), промышленные роботы (Н. Ф. Дюдяев), энергетический фактор производства (В. Ф. Байнев), оборудование для деревообработки (Е. А. Дадеркина) $[3 ; 4 ; 5 ; 6 ; 7]$. С учетом того, что строительная индустрия - важнейшая отрасль реального сектора экономики любой современной державы, предпринятое в данной статье распространение потребительно-стоимостного (полезностного) метода исследований на новую предметно-объектную область - стройиндустрию является очередным шагом в развитии данного перспективного направления экономической теории.

\section{РЕЗУЛЬТАТЫ И ИХ ОБСУЖДЕНИЕ}

\section{Проблемы функционирования стройиндустрии и актуальность полезностной (потребительно-стоимостной) концепџии экономической теории при их решении}

Как известно, строительная индустрия - важнейшая отрасль реального сектора экономики любой современной державы, включая Республику Беларусь, где удельный вес строительной отрасли в ВВП достаточно велик, составляя величину, достигавшую в отдельные годы $10 \%$.

К сожалению, приходится констатировать, что в последнее время в отечественной строительной индустрии, как и в национальной экономике в целом, наблюдались негативные процессы, выразившиеся в нестабильном, неритмичном развитии отрасли. Так, за один только кризисный 2011 г. удельный вес строительной отрасли в ВВП сократился почти в 1,5 раза - с 9,4 до 6,5 \%. После трехлетнего относительно благополучного периода восстановления отрасли, когда за 2012-2015 гг. ее доля в ВВП выросла с 6,5 до 10,4 \%, вновь настал период спада. В результате по итогам первого полугодия 2017 г. этот показатель составил лишь скромные 5 \% [8].

Анализ показывает, что проблемы строительной отрасли обусловлены не только внешними факторами - негативным влиянием финансового кризиса, но и внутренними причинами, которые, на наш взгляд, имеют системный характер и потому требуют особого подхода при их решении. Считается, что в настоящее время кризисные процессы в белорусской экономике практически преодолены, поскольку даже по итогам первого полугодия 2017 г. положительная динамика по объемам производства и прибыли наблюдалась во всех ее отраслях, за исключением, однако, организаций Министерства строительства и архитектуры Республики Беларусь, где общая сумма чистых убытков составила 60 млн руб. Вместо запланированного роста объемов строительно-монтажных работ, наоборот, получено их снижение на $1 \%$ - до 91,5 \% к первому полугодию 2016 г. Также снизилось и производство стройматериалов: извести произведено на 4 \% меньше, 
кирпичей и блоков строительных - на 3 \%, бетона - на 15 \% меньше, нежели за аналогичный период 2016 г.

Важная деталь - указанные негативные процессы наблюдаются в условиях профицита (избытка) финансовых ресурсов, предназначенных для развития строительной отрасли. Так, не используются запланированные для строительной отрасли льготные кредиты Банка развития, общий объем которых за первое полугодие 2017 г. был освоен лишь на 32,7 \%. Точно так же из 369 млн руб., предусмотренных для инвестирования в строительство объектов АПК в рамках госпрограммы «Агробизнес-2020», было освоено только 82 млн руб., или 22 \% от общего объема запланированных данной программой средств.

Однако наибольшие «зависшие» суммы - это суммы по новым проектам, запланированным к финансированию Банком развития на условиях конкурса. Так, из 105 млн руб., предназначенных для строительства молочно-товарных ферм в объеме 60 млн рублей, комплексов по откорму свиней (23 млн рублей), реконструкцию плодоовощных хранилищ (12 млн рублей) и комбикормовых производств (10 млн рублей), по итогам первого полугодия 2017 г. вообще не было выдано ни одного рубля [9]. Причина столь низкого освоения запланированных для развития строительной отрасли финансовых ресурсов - острый дефицит обладающих необходимой общественной полезностью, а значит, экономически эффективных проектов.

Следует отметить, что в настоящее время проблемы функционирования строительной отрасли актуальны не только для Беларуси, но и для других стран, включая государства ближнего и дальнего зарубежья. По мнению исследователей, профессионально занимающихся экономическими проблемами функционирования стройиндустрии, общими как для стран постсоветского пространства, включая нашу Беларусь, так и ЕС являются проблемы ценообразования [10]. По нашему мнению, именно проблемы в сфере ценообразования во многом стали причиной кризиса в стройиндустрии.

Дело в том, что во время кризисов затраты компаний растут, а столкнувшиеся с недостатком средств потребители, выбирая товары, все больше ориентируются на их цены. Поэтому в условиях экономического спада установление правильных (адекватных) цен - весьма непростая задача: спрос сокращается, образуются излишки мощностей, а потребители стремятся приобретать более дешевые товары, что обычно снижает цены. Что касается производителей, то указанное снижение цен на их конечную продукцию, как правило, частично компенсируется уменьшением затрат в сфере поставок и производства, что связано с удешевлением сырья и материалов из-за общего замедления деловой активности. Нетипичная особенность нынешнего спада в строительной отрасли характеризуется тем, что в последнее время спрос со стороны конечных потребителей снижается, цены на конечную продукцию стройиндустрии уменьшаются, а цены на сырье и материалы, наоборот, растут.

При этом отмечается, что сегодня в Беларуси созданы крупные строительные мощности, в том числе для возведения жилых зданий, однако в настоящее время из-за изменений рыночной конъюнктуры и трудностей со сбытом эти мощности задействованы не до конца. Иными словами, проблематика формирования на рынке объективной, экономически обоснованной стоимости (цены) возводимых объектов строительства и оказываемых строительных услуг, которая, как известно, напрямую связана с их общественной полезностью (потребительной стоимостью), является важной и актуальной задачей как для Беларуси, так и других стран ближнего и дальнего зарубежья. Кроме того, на передний план выдвигается и задача адекватной оценки эффективности использования производственных мощностей, учитывающей не только стоимостные, но и их полезностные (потребительно-стоимостные) характеристики. Иными словами, проблематика 
определения общественной полезности инвестиционных проектов, строительно-монтажных работ, строительных объектов, соответствующих производственных мощностей, строительной техники, становится значимой и актуальной.

О том, что при определении целесообразности реализации того или иного инвестиционного проекта важно учитывать его полезностные характеристики, свидетельствует следующий показательный пример. Как известно, в последнее время трудности и проблемы функционирования организаций в самых разных сферах экономической деятельности, включая стройиндустрию, принято объяснять негативным влиянием мирового экономического кризиса. Конечно, падение спроса на продукцию реального сектора экономики из-за общего спада деловой активности и доходов населения негативно сказывается на рынке недвижимости и, соответственно, на результативности функционирования строительной сферы.

Однако, на наш взгляд, было бы ошибкой объяснять описанные выше негативные процессы исключительно внешними для стройиндустрии факторами, поскольку даже в строительной сфере организации, занимающиеся, например, утилизацией и переработкой строительных отходов, существенно улучшили свое экономическое положение именно в кризисные для других сфер деятельности годы. Так, известно, что в Беларуси за последние четыре года общий объем отходов увеличился с 38 до 42 млн т, или с 3,9 до 4,3 т на одного жителя в год, что свидетельствует о быстро растущей актуальности проблемы удаления и переработки мусора, в том числе строительного.

Так, согласно данным Министерства природных ресурсов и охраны окружающей среды Республики Беларусь, ежегодно в нашей стране образуется и вывозится в места захоронения и переработки около 500 тыс. т строительных отходов, из которых до 90 \% отправляется на переработку с целью их вторичного использования. При этом следует учесть, что удаление со строительных площадок 1 т строительного мусора обеспечивает примерно 12 руб. чистой прибыли, а вовлечение во вторичный оборот 1 т строительных отходов путем их переработки дает еще больший эффект - до 15 руб. чистой прибыли. Таким образом, можно подсчитать, что отечественные организации, задействованные в данном виде в целом переживающего далеко не лучшие времена строительного бизнеса, ежегодно получают в общей сложности более 12,5 млн руб. чистой прибыли при средней рентабельности активов до 45-50 \%.

На наш взгляд, данный парадокс объясняется тем, что удаление, переработка и утилизация строительного мусора - это услуга, характеризующаяся высокой общественной полезностью (потребительной стоимостью), поскольку на сегодняшний день решение экологических проблем цивилизации является одной из наиболее злободневных проблем всего человечества. Следовательно, использование полезностного (то есть учитывающего полезность, потребительную стоимость продуцируемых товаров, работ, услуг) подхода к анализу экономических процессов - это ключ к устойчивому, бескризисному развитию как конкретных строительных организаций, так и национальной и мировой экономики в целом.

\section{Полезностный (потребительно-стоимостный) метод оиенки эффективности: его иеели, сущность и использование в стройиндустрии}

Отправным пунктом наших теоретических исследований являются следующие основные положения трудовой теории потребительной стоимости (В. Я. Ельмеев и др.), лежащие в основе потребительно-стоимостного анализа эффективности технико-технологического прогресса: 
1. Всякий продукт (товар, услуга, работа) имеет двойственную природу, поскольку, с одной стороны, обладает вполне определенной стоимостью, а с другой - выступает в качестве носителя полезности (является потребительной стоимостью). Как известно, в политической экономии под стоимостью продукта (блага) в самом общем виде принято подразумевать некую количественную пропорцию, исходя из которой собственник (производитель) какого-либо продукта (блага) добровольно обменивает его на другой нужный ему продукт. При этом сторонники трудовой теории потребительной стоимости придерживаются трудового подхода к измерению стоимости продукта, оценивая ее (общественно необходимыми) затратами труда (рабочего времени), необходимого для воспроизводства анализируемого блага. Иными словами, с позиций потребительно-стоимостной концепции экономической теории, также как и с точки зрения трудовой теории К. Маркса, стоимость является вполне объективной и количественно измеримой категорией.

2. Что касается полезности (потребительной стоимости) продукта, то под ней, как известно, понимается его способность удовлетворять какую-либо человеческую потребность. К сожалению, подавляющее большинство экономистов считают полезность (потребительную стоимость) сугубо субъективной экономической категорией, зависящей от индивидуальных предпочтений потребителя, условий использования блага, его редкости и т. Д. При этом в качестве неоспоримых доказательств субъективного характера полезности обычно приводятся вполне убедительные примеры наподобие тех, что перечислены ниже. Так, вполне очевидно, что сигареты (алкоголь, наркотики) удовлетворяют весьма насущную потребность одного человека, однако они совершенно бесполезны (и даже вредны) для другого. Валенки, обладающие исключительно высокой полезностью в морозную погоду, становятся ненужными в летнюю жару, а босоножки, наоборот, носят летом и прячут в шкаф зимой. С точки зрения теории предельной полезности, лежащей в фундаменте нынешнего «экономического мейнстирма», первая коврига хлеба приносит голодному человеку намного больше пользы, нежели вторая, третья и тем более сотая. Получается, что полезность этой самой ковриги - весьма изменчивая величина, зависящая не только от предпочтений потребителя, но и от редкости данного блага. Иными словами, эти и множество других подобных примеров заставляют большинство из нас считать, что полезность (потребительная стоимость) - субъективная, количественно неизмеримая категория.

Несмотря на это трудовая теория потребительной стоимости утверждает, что полезность (потребительная стоимость) блага, равно как и его стоимость, является объективной, а значит, количественно измеримой величиной. При этом сторонники данного направления экономической теории, подразделяя блага на средства (факторы) производства и предметы потребления, разработали концептуальные, теоретико-методологические и даже методические основы количественного измерения полезности пока только средств (факторов) производства. Проблема же количественного анализа и объективного сопоставления полезности предметов потребления пока еще находится в стадии научной разработки и концептуально решена лишь для некоторых из них (например, для продуктов питания, исходя из их калорийности, насыщенности белками, жирами, углеводами, микроэлементами, витаминами и т. п.).

3. При оценке полезности средств производства развивающая марксизм потребительно-стоимостная концепция экономической теории исходит из того фундаментального положения, что политико-экономическая миссия технико-технологического прогресса в целом и назначение его конкретных достижений сводится, в конечном счете, к повышению производительности труда. Не случайно одним из стержневых положений советской (марксистско-ленинской) политэкономии был тезис о том, что «производи- 
тельность труда, это, в последнем счете, самое важное, самое главное для победы нового общественного строя» [11, с. 21]. По словам крупнейшего экономиста-теоретика К. Маркса, «экономия времени остается первым экономическим законом на основе коллективного производства» [12, с. 117].

И действительно, производственное оборудование, транспортные средства, бытовая техника и т. д. имеют одно и то же общее предназначение - облегчать условия труда и быта человека, сберегать его труд, мускульную и умственную энергию и, в конечном счете, экономить рабочее время. Исходя из этого, сторонники трудовой теории потребительной стоимости делают фундаментальный вывод о том, что полезность (nотребительная стоимость) всякого фактора производства заключается в его способности экономить собой живой труд человека, экономить его рабочее время. Получается, что количественно величина полезности (потребительной стоимости) определяется тем объемом рабочего времени, которое позволяет сэкономить тот или иной фактор производства при его производственном использовании.

Так, предположим, что рытье котлована под фундамент жилого дома лопатой вручную требует затрат живого (простого) труда в объеме 10000 человеко-часов (чел.'ч.), а экскаваторщик на экскаваторе выполняет данную работу всего за 10 чел.'ч. Это означает, что в данном конкретном случае полезность использования экскаватора определяется объективной и вполне измеримой количественно величиной - объемом живого труда в объеме около 9990 чел.'ч., который заместит (сэкономит) экскаватор при рытье котлована. Сэкономленное рабочее время - это и есть единственное то, ради чего строительная компания приобретает и использует дорогостоящий экскаватор вместо дешевой, но малопроизводительной лопаты.

Очевидно, что полезность экскаватора (и любой другой техники) определяется тем общим количеством живого труда, который сэкономит его владельцу эта машина за весь срок ее использования. Так, если одна машина за весь срок ее эксплуатации способна сэкономить ее владельцу 1 млн чел.'ч., а вторая - в два раза меньше, то и полезность второй машины соответственно в два раза меньше, нежели первой. Заметим, что с учетом вполне определенной стоимости каждого человеко-часа простого труда сэкономленное время оборачивается для использующего технику предпринимателя соответствующей экономией его финансовых ресурсов.

4. При анализе описанного выше случая использования экскаватора следует учесть, что экскаватор замещает 10000 чел.'ч. простого труда землекопа, однако требует 10 чел.'ч. сложного труда экскаваторщика, поскольку тот является работником более высокой квалификации, нежели землекоп. Поэтому для сопоставления трудозатрат экскаваторщика и землекопа приходится использовать метод редукции труда - приведения сложного труда к простому. Проще всего указанную редукцию осуществить, сводя сложный труд экскаваторщика, положим, VI-го квалификационного разряда к простому труду землекопа І-го квалификационного разряда с использованием соответствующего тарифного коэффициента из Единой тарифной сетки, равного 1,9. С учетом этого, полезность использования экскаватора в описанном выше конкретном случае окажется меньше вычисленного нами значения и составит лишь $(10000-10 \times 1,9)=9981$ чел.' простого труда. Понятно, что при исчислении полезности использования экскаватора за весь срок его службы точно так же следует учитывать не только обеспечиваемую им экономию простого труда за этот период, но и сопутствующие трудозатраты сложного труда экскаваторщика, а также других обслуживающих машину работников.

5. При расчете полезностного (потребительно-стоимостного) экономического эффекта от эксплуатации экскаватора нельзя игнорировать тот факт, что, хотя эта машина и экономит живой труд, однако ее создание и текущее обслуживание (например, ремонт, 
заправка топливом и т. п.) требует намного больше трудозатрат по сравнению с вариантом, связанным с использованием лопаты. Это значит, что при исчислении полезностного экономического эффекта в виде обеспечиваемой экскаватором экономии труда из его полезности (см. выше) необходимо вычесть затраты прошлого труда, овеществленного в экскаваторе в процессе его создания, то есть стоимость экскаватора. Точно так же мы должны учитывать и затраты прошлого труда, овеществленного в расходуемом экскаватором топливе и прочих расходных материалах.

Таким образом, полезностный (потребительно-стоимостный) экономический эффект от эксплуатации строительной техники определяется абсолютной экономией совокупного (живого и прошлого) труда, который обеспечивает эта техника обществу за весь срок ее эксплуатации. Заметим, что данный эффект одновременно учитывает в себе как полезностные характеристики строительной техники (экономию живого труда), так и стоимостные параметры (затраты прошлого труда, овеществленного в технике и потребляемых ею расходных материалах). Следовательно, полезностный (потребительно-стоимостный) анализ комплексно учитывает все аспекты функционирования строительной техники, поскольку требование максимизации полезностного экономического эффекта одновременно нацеливает на: а) увеличение полезности (производительности) техники в качестве экономии живого труда, которая будет обеспечена техникой у потребителя; б) экономию расходных материалов (например, горюче-смазочных, запчастей, электроэнергии, воды и т. п.) при эксплуатации техники потребителем; в) уменьшение ее стоимости, то есть затрат прошлого труда, затраченного производителем на изготовление техники.

Поскольку современная стройиндустрия использует большое количество разнообразных строительных машин, эффективность работы которых во многом определяет результаты функционирования отрасли в целом, описанная методология полезностной оценки эффективности новой техники может и должна быть использована для разработки соответствующей методики.

\section{Методические основы оценки полезностного эффекта и полезностной экономической эффективности строительных машин}

На сегодняшний день человечество не сможет обойтись без машин, потому что они играют важную роль в современном мире. Машина - совокупность технических устройств и механизмов, работающих как единое целое и совершающих определенные механические движения и тем самым выполняющих технологически полезную работу за счет преобразования тепловой, химической, электрической, ядерной энергии в механическую работу. Категории «техника» и «оборудование», включают в себя машины, но не ограничиваются этим. Так, экскаватор, являясь машиной, подпадает под определения «техника» и «оборудование». Однако, например, осветительное оборудование, не имея движущихся частей, машиной не является. Таким образом, под техникой и оборудованием мы будем подразумевать совокупность устройств и механизмов, работающих как единое целое и выполняющих технологически полезную работу за счет преобразования тепловой, химической, электрической, ядерной энергии в какой-либо другой вид энергии, требуемой для осуществления производственного процесса.

Оборудование, технику (технические факторы производства), как правило, применяют с целью облегчения человеческого труда или его полной замены на основе вовлечения в производственные процессы природной энергии. Иными словами, основной целью, предназначением технико-технологического прогресса и конкретных его достижений, в частности, является повышение производительности труда через замещение 
в производственных процессах поначалу мускульной (физической) энергии человека, а в последнее время и его управленческих и интеллектуальных функций [13]. То есть в соответствии с полезностной (потребительно-стоимостной) концепцией экономической теории [3] полезность (потребительная стоимость) техники определяется объемом живого труда, который она высвобождает из производственных процессов за весь срок ее эксплуатации, о чем уже шла речь выше.

В наши дни машины, технику, оборудование используют во всех без исключения сферах экономической деятельности, включая строительство. При разработке методических основ оценки полезностного эффекта и полезностной эффективности строительной техники необходимо учитывать ее многообразие и функциональное предназначение ее отдельных видов.

В связи с этим вся строительная техника может быть классифицирована по основным видам строительных работ на следующие группы: транспортирующие машины; погрузочно-разгрузочная техника; грузоподъемные машины; техника для земляных работ; оборудование для свайных работ; техника для дробления, сортировки и мойки каменных материалов; оборудование для приготовления, транспортирования бетонов и растворов и уплотнения бетонной смеси; оборудование для отделочных работ; оборудование специального назначения (освещение, обогрев помещений, размораживание грунта, вентиляция и кондиционирование воздуха и т. п.); ручной механизированный инструмент, предназначенный для выполнения различных видов работ в строительстве.

При этом принципиальным моментом является понимание того, что труд человека в строительстве замещяает собой отнюдь не техника, а потребляемая ею природная энергия. Техника в процессе такого замещения выполняет всего лишь роль вещественного посредника, транспортирующего природную энергию к месту требуемого воздействия на предметы труда и преобразующего ее в форму, необходимую для такого воздействия. Например, при рытье котлована под фундамент с помощью экскаватора соответствующую механическую работу по требуемому поднятию-перемещению грунта вместо мускулов землекопа с лопатой осуществляет химическая энергия топлива, которая с помощью системы входящих в экскаватор механизмов преобразуется в кинетическую энергию движения его ковша. А при поднятии-перемещении тяжестей с помощью строительного электрического крана данную механическую работу вместо мускулов человека выполняет электроэнергия, преобразуемая системой электроприводов в соответствующие перемещения строительного крюка с подвешенным к нему грузом вдоль трех осей координат. При этом очевидно, что чем больше природной энергии вовлечено с помощью техники в производственный процесс, тем большее количество работников она собою замещает и, соответственно, тем выше производительность труда.

Несмотря на все многообразие строительной техники (см. выше) ее можно классифицировать на две большие группы по виду потребляемой, вовлекаемой в производственный процесс природной энергии: 1) топливосжигающая строительная техника (оборудование); 2) электрифицированная строительная техника (оборудование). Таким образом, методика расчета полезностного эффекта и полезностной экономической эффективности строительной техники должна учитывать данную классификацию и, соответственно, принимать во внимание специфические особенности представленной в ней техники.

\section{Методика расчета полезностного эффекта и полезностной экономической эффективности строительной техники}

Как это было отмечено выше, в самом общем виде полезностный экономический эффект от использования техники (включая строительную - электрифицированную 
и топливосжигающую) определяется абсолютной экономией совокупного (живого и прошлого) труда, который обеспечивает эта техника за весь срок ее эксплуатации. Иными словами, если из полезности техники, характеризующей абсолютную экономию обеспечиваемой ею живого труда, вычесть ее стоимость - затраты овеществленного в этой технике прошлого труда, то это и будет полезностный экономический эффект от использования техники.

Сразу же оговоримся о следующем - поскольку для большинства стран мира известна минимальная или средняя стоимость человеко-часа в их экономиках, то определение указанного выше полезностного эффекта принципиально возможно осуществлять как в трудовых (чел.'ч), так и в денежных единицах (ден. ед.). Однако, следует учесть, что затраты овеществленного в технике труда (ее стоимостные характеристики) общепринято выражаются в денежных единицах, которые к тому же более привычны для их восприятия предпринимателями, нежели трудовые единицы. Исходя из этого, в дальнейшем при определении полезности техники и полезностного эффекта от ее использования мы также будем пользоваться денежными единицами.

Очевидно, что общий (суммарный) полезностный эффект от использования техники за весь срок ее эксплуатации будет зависеть от величины этого эффекта за год и, соответственно, числа лет эксплуатация техники:

$$
T U E=U E \cdot T,
$$

где TUE (Total Utility Effect) - общий (суммарный) полезностный эффект от использования техники за весь срок ее эксплуатации, ден. ед.;

$U E(U s e f u l$ Effect) - годовой полезностный эффект от использования техники, ден. ед.;

$T$ - срок эксплуатации техники, годы.

В свою очередь, годовой полезностный эффект от использования техники может быть определен следующим образом:

$$
U E=U C E-C C E,
$$

UCE (Usefulness of Construction Equipment) - годовая полезность строительной техники, ден. ед.;

CCE (Cost of Construction Equipment) - годовая стоимость использования строительной техники, ден. ед.

Годовая полезность техники определяется как абсолютная экономия живого труда, достигаемая в процессе ее эксплуатации в течение года:

$$
U C E=S L L-O L C
$$

где SLL (Substitution of Living Labor) - годовое замещение природной энергией живого труда, осуществляемое при посредничестве техники, ден. ед.;

OLS (Operator Labor Costs) - годовые затраты живого труда операторов техники, учитываемые их годовой заработной платой, ден. ед.

Замещение живого труда природной энергией, выделяемой в процессе сжигания углеводородов при использовании топливосжигающей техники, рассчитывается с учетом коэффициентов полезного действия и полезной загрузки анализируемого оборудования:

$$
\begin{gathered}
S L L=C L \cdot \frac{\mathrm{c} \cdot F C \cdot \rho}{e \cdot E E S W} \cdot \eta \cdot P F \cdot t, \\
28
\end{gathered}
$$


где SLL (Substitution of Living Labor) - объем замещения живого труда природной энергией при посредничестве техники, ден. ед.; $C L$ - стоимость человеко-часа живого труда, ден. ед./чел.'ч; FC (Fuel Consumption) - расход топлива, л/ч; c- удельная теплота сгорания углеводородного топлива, Дж/кг; $\rho$ - удельный вес углеводородного топлива, кг/л; $e$ - энергетическая константа преобразования энергетических единиц друг в друга, $\mathrm{e}=3.6 * 10^{6}$ Дж/кВт*ч.; EESW (Energy Equivalent of a Simple Worker) - энергетический эквивалент занятого простым трудом человека, $E E S W=0,141$ кВт/чел. [14, с. 252]; $\eta$ коэффициент полезного действия оборудования; PF (Payload Factor) - коэффициент полезной загрузки строительной техники, учитывающий ее производительность, а также холостой ход ее узлов и механизмов; $t$-время использования техники в течение года, ч.

Замещение живого труда электрической энергией в случае использования электрифицированной строительной техники рассчитывается с учетом ее полной электрической мощности:

$$
S L L=C L \cdot \frac{P}{E E S W} \cdot \eta \cdot \cos \varphi \cdot P F \cdot t
$$

где $P$ - полная электрическая мощность техники, кВт;

$\cos \varphi$ - технический коэффициент мощности электрооборудования строительной техники.

В свою очередь, годовая стоимость использования строительной техники в формуле (2) учитывает все затраты прошлого труда, овеществленного в этой технике:

$$
C C E=A M+L C S+C C,
$$

где AM (Amortization of Machinery) - годовая амортизация техники, ден. ед.;

LCS (Labor Costs of the Staff) - годовые затраты прошлого труда персонала, овеществленные в налаживаемой и обслуживаемой им технике и учитываемые в виде годовой зарплаты наладчиков и прочего обслуживающего персонала (в расчете на анализируемую единицу техники), ден. ед.;

CC (Cost of Consumables) - годовая стоимость расходуемых энергоресурсов и сопутствующих материалов, обеспечивающих функционирование техники (смазки, сжатого воздуха, технических жидкостей и т. п.), ден. ед.:

$$
C C=C E R+C R M
$$

где CER (Cost of Energy Resources) - годовая стоимость израсходованных энергоресурсов, ден. ед.;

CRM (Cost of Related Materials) - годовая стоимость израсходованных сопутствующих материалов, ден. ед.

Годовая стоимость израсходованных энергоресурсов зависит от их годового расхода и цены (тарифа):

а) в случае использования топливосжигающей техники:

$$
C E R=F P F C \cdot t
$$

где FP (Fuel Price) - цена топлива, ден. ед./л;

б) при эксплуатации электрифицированной техники: 


$$
C E R=P E \cdot P \cdot t,
$$

где PE (Price of Electricity) - тариф на электроэнергию, ден. ед./кВт`ч.

Полезностная экономическая эффективность использования строительной техники определяется в виде соотношения достигнутого полезностного экономического эффекта и стоимости ее использования:

$$
U E E=\frac{U E}{C C E},
$$

где UEE (Useful Economic Efficiency) - полезностная экономическая эффективность использования строительной техники, разы (может быть также выражена в процентах).

В процессе апробации методики, представленной выражениями (1)-(8), нами проанализированы выпущенные разными производителями образцы строительной техники, предназначенной для приготовления строительных смесей (растворов, бетонов и т. д.). При осуществлении расчетов мы учли стоимость 1 человеко-часа простого труда, рассчитанную исходя из месячной минимальной заработной платы в Республике Беларусь, равной 305 руб. (согласно Постановлению Совета Министров Республики Беларусь от 28 декабря 2017 г. № 1022). Стоимость 1 человека-часа квалифицированного труда оператора бетономешалки III разряда и обслуживающего ее наладчика V разряда определялась с использованием Единой тарифной сетки Республики Беларусь. Результаты расчетов по данной методике представлены в табл. 1.

Таблица 1 - Полезностный экономический эффект и полезностная экономическая

\begin{tabular}{|c|c|c|c|c|c|c|c|}
\hline $\begin{array}{c}\text { Наименование } \\
\text { техники }\end{array}$ & 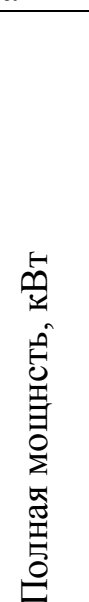 & \begin{tabular}{l}
5 \\
\multirow{2}{5}{} \\
0 \\
0 \\
0 \\
0 \\
0 \\
0 \\
0 \\
0 \\
0 \\
0 \\
0 \\
0 \\
0 \\
0 \\
0 \\
0 \\
0 \\
0 \\
0
\end{tabular} & 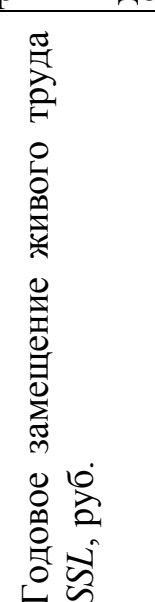 & 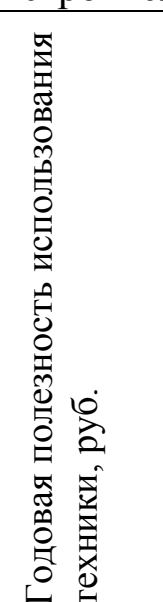 & 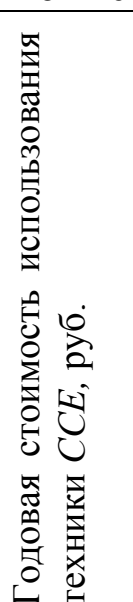 & 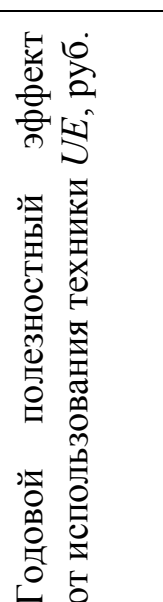 & 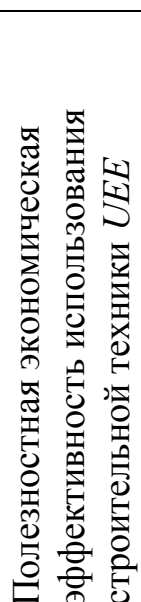 \\
\hline $\begin{array}{l}\text { Бетономешалка DGM } \\
\text { ВK-190 (Россия) }\end{array}$ & 0,75 & 1,5 & 7266,79 & 3150,69 & 538,05 & 2612,64 & 4,85 \\
\hline $\begin{array}{l}\text { Бетономешалка ЕСО } \\
\text { СМ-190 (Китай) }\end{array}$ & 1,0 & 1,5 & 7811,36 & 3695,26 & 555,13 & 3140,13 & 5,66 \\
\hline $\begin{array}{l}\text { Бетономешалка Altrad } \\
\text { SPOMASZ MK-180 } \\
\text { (Польша) }\end{array}$ & 0,9 & 1,2 & 5848,89 & 1732,79 & 531,18 & 1201,61 & 2,26 \\
\hline
\end{tabular}
эффективность использования некоторых видов строительной техники

Источник: разработка авторов.

Отраженные в табл. 1 показатели полезностной экономической эффективности использования проанализированных образцов строительной техники (бетономешалок) показывают во сколько раз предпринимателю экономически выгоднее использовать бетономешалку и наемный труд управляющего ею оператора III разряда по сравнению 
с вариантом, когда тот же самый объем строительной смеси приготовлялся бы (замешивался) наемными чернорабочими I разряда вручную.

\section{ВЫВОДЫ}

1. Многие глобальные (сырьевая, энергетическая, экологические и др.) проблемы цивилизации, на наш взгляд, возникли и до предела обострились по причине несовершенства традиционных (стоимостных) методов оценки эффективности технико-технологического прогресса. Использование прибыли и ее производных в качестве главного критерия оценки эффективности технических и иных достижений нередко толкает предпринимателей на реализацию выгодных для них, однако, малополезных или же вообще вредных для окружающей среды и социума проектов. В связи с этим развитие теории и практики полезностной оценки экономической эффективности является актуальной задачей экономической науки в противоречивом XXI веке.

2. Проблемы функционирования строительной отрасли точно также во многом обусловлены доминированием в данной сфере экономики традиционных (стоимостных) методов оценки экономической эффективности. Поставленная и решенная в статье задача разработки методических основ и рабочей методики определения полезностного экономического эффекта и полезностной экономической эффективности строительной техники, по нашему мнению, сможет решить или хотя бы смягчить часть терзающих стройиндустрию проблем. При решении указанной задачи мы опирались на полезностную (потребительно-стоимостную) концепцию экономической теории (В. Ельмеев и др.), оценивающую полезность всякого фактора производства объемом живого труда, который позволяет сэкономить данный фактор в процессе его производственного использования.

3. Осуществленное в статье и, на наш взгляд, успешное распространение основных положений полезностной (потребительно-стоимостной) экономической теории на новую предметно-объектную область - стройиндустрию - доказывает результативность и перспективность данного направления экономической теории. При решении глобальных проблем цивилизации нам неизбежно придется ориентироваться не на максимизацию прибыли, которая со всей очевидностью является достоянием лишь немногих избранных, а на удовлетворение фундаментальных, по-настоящему насущных потребностей большинства населения планеты Земля, что возможно только в рамках потребительно-стоимостной социально-экономической парадигмы.

\section{СПИСОК ИСПОЛЬЗОВАННЫХ ИСТОЧНИКОВ}

1. Schwab, K. The Fourth Industrial Revolution / K. Shcwab // Foreign Affairs. December 12, 2015 [Электронный ресурс]. - Режим доступа: https://www.foreignaffairs.com/ articles/2015-12-12/fourth-industrial-revolution - Дата доступа: 05.01.2018.

2. Солодовников, С. Ю. Теоретико-методологические основы исследования социального капитала как политико-экономического феномена / С. Ю. Солодовников // Экономическая наука сегодня: сборник науч. ст. - Выпуск № 5. - Минск БНТУ, 2017. - С. 6-56.

3. Ельмеев, В. Я. Социальная экономия труда (Общие основы политической экономии) / В. Я. Ельмеев. - СПб.: Изд-во С.-Петерб. ун-та, 2007. - 576 с.

4. Байнев, В. Ф. Научно-технический прогресс и энергосбережение: потребительно-стоимостный анализ эффективности производства электроэнергии: монография / В. Ф. Байнев. - Саранск: Изд-во Мордов. ун-та, 1998. - 92 с.

5. Байнев, В.Ф. Электропотребление и экономия живого труда: потребительно-стоимостный анализ: монография / В. Ф. Байнев. - Саранск: Изд-во Мордов. ун-та, 1998. - 88 с. 
6. Дюдяев, Н. Ф. Промышленные роботы и экономия живою труда. Потребительностоимостный анализ / Н. Ф. Дюдяев. - Саранск: Изд-во Мордов. ун-та. 1991. - 164 с.

7. Байнев, В. Ф. Научно-технический прогресс и устойчивое развитие: теория и практика полезностной (потребительно-стоимостной) оценки эффективности новой техники: монография / В. Ф. Байнев, Е. А. Дадеркина; под общ. ред. В. Ф. Байнева; Белорусский государственный университет. - Минск: Право и экономика, 2008. - 189 с.

8. Национальный статистический комитет Республики Беларусь // Оперативные данные. [Электронный ресурс] - Режим доступа: http://www.belstat.gov.by/ofitsialnayastatistika/makroekonomika-i-okruzhayushchaya-sreda/natsionalnye-scheta/operativnaya-infor matsiya_5/- Дата доступа 15.12.2017.

9. Новости Беларуси [Электронный ресурс] // Оперативные данные - Режим доступа: https://news.regiony.by/\#!news/12232 - Дата доступа 22.01.2018.

10. Специфические проблемы строительной отрасли Беларуси // Строительная газета. 09 июля 2015 г. [Электронный pecypc]. - Режим доступа: http://cnb.by/ servisy/mneniya/specificheskie-problemy-stroitel-noj-otrasli-belarusi.html - Дата доступа: 15.12.2017.

11. Ленин, В. И. Великий почин / В. И. Ленин // Полное собрание сочинений; 5-е изд. - Т. 39. - М.: Изд-во политической литературы, 1970. - 623 с.

12. Маркс, К. Экономические рукописи 1857-1859 годов / К. Маркс, Ф. Энгельс. Соч. 2-е изд. - Т. 46. - Ч. І. - 560 с.

13. Байнев, В. Ф. Четвертая промышленная революция как глобальный инновационный проект / В. Ф. Байнев // Наука и инновации. - Минск, 2017. - № 3 - С. 38-41.

14. Бесчинский, А. А. Экономические проблемы электрификации / А. А. Бесчинский, Ю. М. Коган. - М.: Энергоатомиздат, 1983. - 432 с.

\section{REFERENCES}

1. Schwab, K. The Fourth Industrial Revolution / K. Shcwab // Foreign Affairs. December 12, 2015 [Ehlektronnyj resurs]. - Rezhim dostupa: https://www.foreignaffairs.com/ articles/2015-12-12/fourth-industrial-revolution - Data dostupa: 05.01.2018.

2. Solodovnikov, S. Yu. Teoretiko-metodologicheskie osnovy issledovaniya social'nogo kapitala kak politiko-ehkonomicheskogo fenomena / S. Yu. Solodovnikov // Ehkonomicheskaya nauka segodnya: sbornik nauch. st. - Vypusk № 5. - Minsk BNTU 2017. - S. 6-56.

3. El'meev, V. Ya. Social'naya ehkonomiya truda (Obshchie osnovy politicheskoj ehkonomii) / V. Ya. El'meev. - SPb.: Izd-vo S.-Peterb. un-ta, 2007. - 576 s.

4. Bajnev, V. F. Nauchno-tekhnicheskij progress i ehnergosberezhenie: potrebitel'nostoimostnyj analiz ehffektivnosti proizvodstva ehlektroehnergii: monogra-fiya / V. F. Bajnev. Saransk: Izd-vo Mordov. un-ta, 1998. - 92 s.

5. Bajnev, V.F. Ehlektropotreblenie i ehkonomiya zhivogo truda: potrebitel'nostoimostnyj analiz: monografiya / V. F. Bajnev. - Saransk: Izd-vo Mordov. un-ta, 1998. - 88 s.

6. Dyudyaev, N. F. Promyshlennye roboty i ehkonomiya zhivoyu truda. Potrebi-tel'nostoimostnyj analiz / N. F. Dyudyaev. - Saransk: Izd-vo Mordov. un-ta. 1991. - 164 s.

7. Bajnev, V. F. Nauchno-tekhnicheskij progress i ustojchivoe razvitie: teoriya I praktika poleznostnoj (potrebitel'no-stoimostnoj) ocenki ehffektivnosti novoj tekhniki: monografiya / V. F. Bajnev, E. A. Daderkina; pod obshch. red. V. F. Bajneva; Belorusskij gosudarstvennyj universitet. - Minsk: Pravo i ehkonomika, 2008. - 189 s. 
8. Nacional'nyj statisticheskij komitet Respubliki Belarus' // Operativnye dannye [Ehlektronnyj resurs]/ - Rezhim dostupa: http://www.belstat.gov.by/ofitsialnaya-statistika/ makroekonomika-i-okruzhayushchaya-sreda/natsionalnye-scheta/operativnaya-informatsiya_5/-Data dostupa 15.12.2017.

9. Novosti Belarusi // Operativnye dannye. [Ehlektronnyj resurs] - Rezhim dostupa: https://news.regiony.by/\#!news/12232 - Data dostupa 22.01.2018.

10. Specificheskie problemy stroitel'noj otrasli Belarusi // Stroitel'naya gazeta. 09 iyulya 2015 g. [EHlektronnyj resurs]. - Rezhim dostupa: http://cnb.by/servisy/mneniya/ specificheskie-problemy-stroitelnoj-otrasli-belarusi.html - Data dostupa: 15.12.2017.

11. Lenin, V. I. Velikij pochin / V. I. Lenin // Polnoe sobranie sochinenij; 5-e izd. T. 39. - M.: Izd-vo politicheskoj literatury, 1970. $-623 \mathrm{~s}$.

12. Marks, K. Ehkonomicheskie rukopisi 1857-1859 godov / K. Marks, F. EHngel's. Soch. 2-e izd. - T. 46. - CH. I. - 560 s.

13. Bajnev, V. F. CHetvertaya promyshlennaya revolyuciya kak global'nyj innovacionnyj proekt / V. F. Bajnev // Nauka i innovacii. - Minsk, 2017. - № 3 - S. 38-41.

14. Beschinskij, A. A. Ehkonomicheskie problemy ehlektrifikacii / A. A. Beschinskij, Yu. M. Kogan. - M.: Ehnergoatomizdat, 1983. - 432 s.

Статья поступила в редакцию 7 марта 2018 года. 